\section{TÀI LIÊU THAM KHẢO}

1. Y. Inoue, "Analysis of acute type A Dissection in Japan Registry of Aortic Dissection (JRAD)," Ann Thorac Surg, vol. 110, pp. 790-8, 2020.

2. M. R. K. Helder, "Regional and Temporal Trends in the Outcomes of Repairs for Acute Type A Aortic
Dissections," Ann Thorac Surg, vol. 109, pp. 2635, 2020.

3. S. J. Bozso, "Midterm Outcomes of the Dissected Aorta Repair Through Stent Implantation Trial," Ann Thorac Surg, vol. 111, pp. 463-71, 2021.

\title{
PHỤC HÌNH TOÀN HÀM CHO BÊ̂NH NHÂN MÒN RĂNG NẶNG
}

\section{TÓM TẮT}

Việc kiểm soát mài mòn răng, đặc biệt là mòn răng nặng đã trở thành một chủ đề ngày càng được quan tâm trong chuyên ngành Răng hàm mặt. Phục hình toàn hàm tác động đến chức năng và thẩm mỹ. Điều quan trọng trong phục hình toàn hàm là xác định đúng kích thước dọc khớp cắn và khoảng nghỉ khớp cắn. Cách tiếp cận có hệ thống để kiểm soát mòn răng giúp tạo tiên lượng thuận lợi, có thể dự đoán trước được. Đây là báo cáo 1 trường hợp lâm sàng bệnh nhẩn bi mòn răng nặng với đề xuất 1 qui trình phục toàn hàm đơn giản, khác biệt.

\section{SUMMARY \\ FULL- MOUTH RESTORATION FOR SEVERE WORN DENTITION PATIENT}

The control of tooth wear, especially heavy tooth wear, is a interesting topic in dentistry. full mouth restoration concern function and aesthetics. It is important in full-mouth restoration to determine the correct occlusal vertical dimension and inter maxillar rest space. A systematic approach controling dental wear provides a favorable, predictable prognosis. This is a report of a clinical case patient with severe worn dentition with a simple proposal procedure.

\section{GIỚl THIỆU}

Mòn răng là thuật ngữ chung sử dụng để mô tả sự mất mô cứng bề mặt của răng do các nguyên nhân khác ngoài sâu răng, chẫn thương hoặc do rối loạn phát triển, thường là do loạn năng khớp thái dương hàm, do sai sót trong điều trị, do thói quen ăn uống và sự thiếu hiểu biết về răng miệng.

Mòn răng là một quá trình sinh lý nhìn thây bằng mắt thường, không thể đảo ngược và tăng dần theo tuổi [1]. Mòn răng gây giảm hiệu suẫt nhai, gây chết tủy....

\footnotetext{
*Trường Đại Hoc Y Dước, ĐHQGHN

**Trướng Đại Học Y Hà Nội

Chịu trách nhiệm chính: Phạm Như Hải

Email: phamnhuhai@yahoo.com

Ngày nhận bài: 5.01.2021

Ngày phản biên khoa học: 25.2.2021

Ngày duyệt bài: 10.3.2021
}

\section{Phạm Như Hải*, Nguyễn Thị Như Trang**}

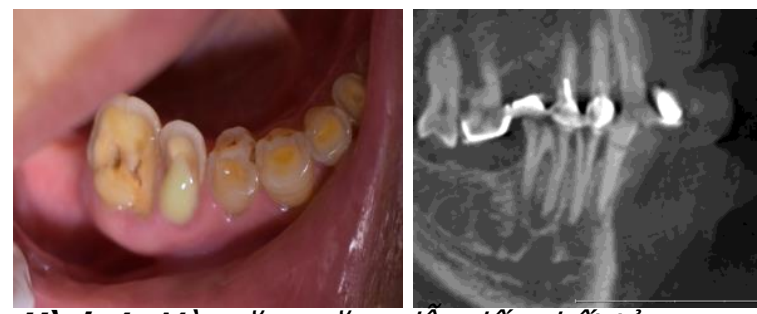

Hình 1: Mòn răng nặng dấn đến chết tủy, nang thân răng, dịch mú trào ra khi mở tủy răng 35 áp xe quanh chóp

Lambrechts và cộng sự. vào năm 1982, ước tính mức độ mất men theo chiêuu đứng do mài mòn sinh lý là khoảng 20-38 um mối năm [2]. Van't Spiiker và cộng sự nghiên cứu thây đàn ông mòn răng nặng hơn đàn bà, mòn răng nặng có thể gặp đến $3 \%$ ở người 20 tuổi và $17 \%$ ở người 70 tuổi. Mòn răng có thể được phân loại nguyên nhân thành cọ mòn, mài mòn và xói mòn, nhưng không phải lúc nào cũng có thể chẩn đoán phân biệt vì trong nhiêuu tình huống, có sự kết hợp của các quá trình này [3]. Trên lâm sàng khó có thể phân lập được một yếu tố căn nguyên duy nhất khi bệnh nhân có biểu hiện mòn răng, vì lý do này Eccles đề xuất vào năm 1982 dùng thuật ngữ "mất tổ chức bề mặt răng" (TSL: tooth surface loss) để ám chỉ tình trạng mòn răng do tất cả các yếu tố căn nguyên bất kể nguyên nhân chính xác của mài mòn đã được xác định hay không. Điêuu này bao gôm các yếu tố như chấn thương, yếu tổ phát triển của răng như tạo men - ngà không hoàn hảo và mòn răng do điều trị.

Trong thực hành lâm sàng hàng ngày, nhiêu bệnh nhân yêu câu làm phục hình để phục hôi khớp cắn do mòn nhiêu răng và mất răng vĩnh viễn sớm. Tuy nhiên, khoảng trống liên hàm thấp tạo ra thách thức cho việc điều trị phục hình cho bệnh nhân mòn răng vì không đủ khoảng cân thiết cho phục hình, dẫn đến hình thể của phục hình mỏng và thấp, không đủ khả năng lưu giữ và chịu lực.

Mục tiêu của phục hình toàn hàm không chỉ 
là tái tạo và phục hồi phần răng bị mòn mà còn là duy trì sức khỏe của toàn bộ hệ thống nhai. Để có thể thực hiện tốt phục hình toàn hàm đòi hỏi các Bác sĩ phưc hình luồn tìm hiểu, nắm bắt và tái tao lại đúng các chuyển đông mô phỏng cơ học của hàm dưới bệnh nhân khi làm phục hình. Việc tái tạo thành công các chuyển động chức năng và không chức năng của bệnh nhân sẽ giúp người Bác sĩ thiết kế và chế tạo chính xác phục hình.

Phục hồi chức năng nhai và thẩm mỹ chấp nhận được là mục tiêu điều trị chính cho phục hình toàn hàm. Tuy nhiên, rất khó để xây dựng một kế hoạch điều trị đáp ứng được tất cả mong đợi của bệnh nhân, do không gian phục hình hạn chế. Bên canh đấy thường đòi hỏi phải kết hợp đa chuyên khoa khi điều trị cho bênh nhân như khớp cắn, nội nha, nha chu và chỉnh nha.... Vì vậy cần khám tư vấn bệnh nhân cẩn thận về mức đô phức tap của điểu tri, khả năng thành công của kỹ thuật, chi phí và thời gian điều trị; để lên kế hoạch phục hình toàn hàm.

Có nhiều triết lý khác nhau trong phục hình toàn hàm [4, 5]: Gnathological concept (McCollum, Stuart, Stallard). Freedom in centric concept (Schuyler), Simplified occlusal design (Wiskott and Belser), Pankey, Mann and Schuyler Philosophy (1960), Twin Table technique-Hobo (1991), Twin Stage ProcedureHobo and Takayama, Youdelis Scheme, Nyman and Lindhe Scheme. Mỗi triết lý điều trị có 1 ưu nhược điểm khác nhau. Triết lý Pankey Mann Schuyler là 1 triết lý được nhiều người áp trong phục hồi khớp cắn. Theo triết lý Pankey Mann Schuyler [4], điều trị phục hình toàn hàm được chia thành 4 giai đoan:

Bước 1: Khám, chẩn đoán, lập kế hoạch điêu trị và tiên lượng.

Bước 2: Hợp lý hóa hướng dẫn răng cửa trước để đạt được thẩm mỹ, chức năng và sự thoải mái nhất có thể.

Bước 3: Lựa chọn mặt phẳng khớp cắn có thể chấp nhận được và phục hồi khớp cắn hàm dưới trước hài hòa với hướng dẫn phía trước, tức là không cản trở hướng dẫn răng cửa và hướng dẫn lồi câu.

Bước 4: Phục hồi khớp cắn răng sau trên hài hòa với hướng dẫn răng cửa trước và hướng dẫn lồi cầu.

Tuy nhiên triết lý điều trị này phải thực hiện qua nhiều bước, mất nhiêu thời gian. Báo cáo của chúng tôi nhằm mục đích đề xuất một qui trình điều trị đơn giản cho các bệnh nhân mòn răng nặng.

\section{BÁO CÁO TRƯờNG HỢP LÂM SÀNG}

Khám: Một phụ nữ 53 tuổi bị mòn răng nặng cả 2 hàm. Lý đến khám là ê buốt răng và răng mòn quá nhiêu. Khám trong miệng cho thấy tình trạng mất tổ chức răng (hình 2), mặt nhai răng hàm có những cạnh men sắc nhọn, hố lõm và mòn gần hết thân răng ở vùng răng hàm lớn.

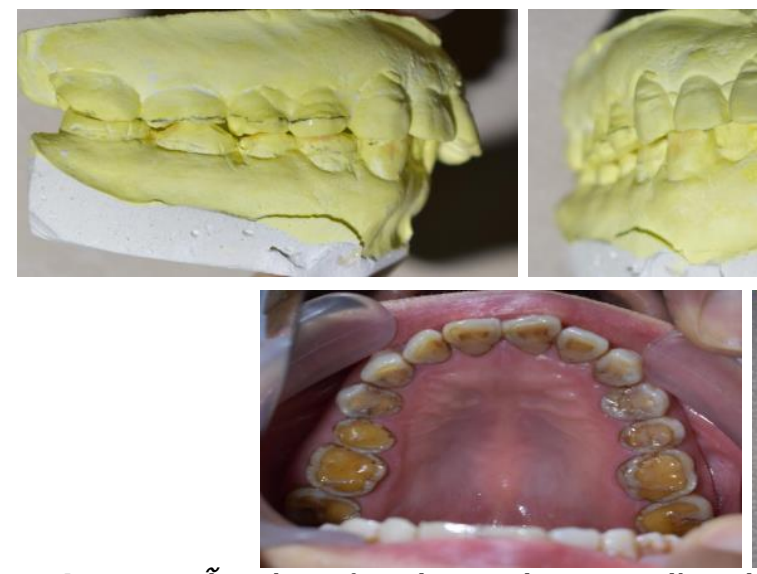

Hình 2: Mẫu hàm của bệnh nhân cho thây thân

Bệnh nhân có tiền sử loạn năng thái dương hàm và đau nhức các cơ nhai, nhưng không có khác biệt giữa khớp cắn trung tâm và vị trí lồng múi tối đa khi bênh nhân được hướng dẫn về tương quan trung tâm với kỹ thuật Dawson thao tác bằng hai tay và 2 tháng đeo máng giãn cơ.

Mẫu hàm trên và dưới được vào giá khớp bán

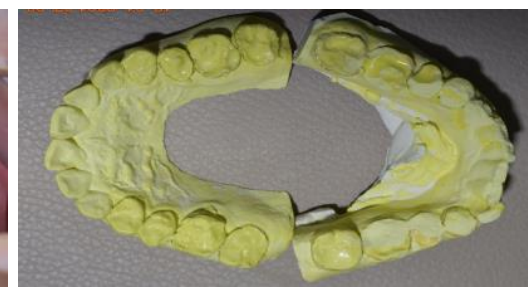

thích ứng (Quick Master, France) với cung mặt và đo độ dốc lồi cầu. Đo khoảng nghỉ giữa 2 hàm, phục hình tam tăng thêm từ $2-4 \mathrm{~mm}$ ở vùng răng cửa trước và $1,5-2 \mathrm{~mm}$ vùng răng hàm.

Dựa trên các dấu hiệu lâm sàng, khoảng phục hình hiện có trên miệng của bệnh nhân chúng tôi xây dựng quy trình điêu trị theo các 
bước [6]:

(a) Máng giãn cơ để xác định tương quan 2 hàm ở vị trí tương quan trung tâm

(b) Tăng kích thước dọc bằng phục hình tạm hàm dưới trong 4 tuần để thích ứng với cơ nhai và khớp thái dương hàm.

(c) Tăng kích thước dọc bằng phục hình tạm hàm trên thêm 4 tuần nữa để đánh giá sự thích ứng của cơ nhai và khớp thái dương hàm

Theo một nghiên cứu tổng quan tác động của việc tăng kích thước dọc, sự gia tăng vĩnh viễn kích thước dọc từ 1 đến $5 \mathrm{~mm}$ là một quy trình an toàn và chấp nhận được [7], các dấu hiệu và triệu chứng liên quan đến khớp thái dương hàm và co thắt cơ sẽ chỉ thoáng qua và có xu hướng hết trong vòng 2 tuần. Mặc dù có thể an toàn để tăng kích thước dọc thêm $5 \mathrm{~mm}$, nhưng trong nghiên cứu này, chúng tôi đã thực hiện công việc thận trọng, tăng tầm cắn chậm, bắt đầu từ hàm dưới trước và quan sát trong 4 tuần để đánh giá sự thích ứng của bệnh nhân. Bệnh nhân được khám lâm sàng hàng tuần. Bệnh nhân cho biết không có cảm giác khó chiu ở khớp thái dương hàm, không đau cơ. Đồng thời cũng đánh giá sự ảnh hưởng của tăng kích thước dọc đến ngoại hình khuôn mặt và phát âm.

Liệu pháp nâng tầm cắn: lấy dấu gứi xưởng để tái tạo khớp cắn 2 hàm với việc tái tạo lại chiều cao thân răng. Làm phục hình nhựa tạm bao phủ toàn bộ mặt nhai của rắng trước và răng sau cả 2 hàm trên và dưới, tăng chiều cao thân răng thêm $2 \mathrm{~mm}$ mỗi hàm, khoảng $4 \mathrm{~mm}$ cho cả 2 hàm. Bênhh nhân được gắn chặt phục hình tạm cho hàm dưới trước, mài chỉnh để tao ra khớp cắn tốt nhất với hàm trên với hướng dẩn răng nanh và hướng dẫn răng cửa. cho bệnh nhân ăn nhai trên phục hình tạm hàm dưới trong 4 tuần.
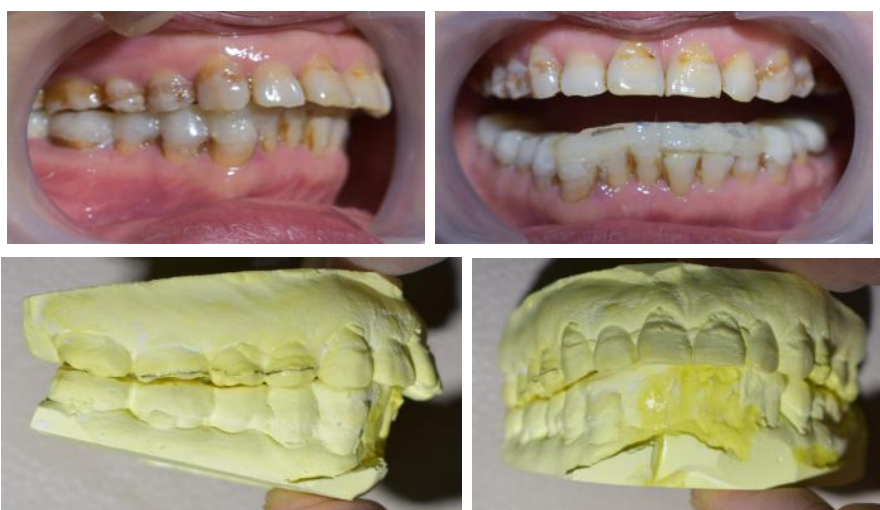

Hình 3: Nâng tầm cắn tr

Hẹn bệnh nhân đến tái khám hàng tuần để mài chỉnh để giúp bệnh nhân ăn uống thoải mái nhất. Sau 4 tuần bệnh nhân ăn uống bình thường bắt đầu làm bước tiếp theo là gắn phục hình tam hàm trên và để cho bệnh nhân ăn trển phục hình tạm này. Đối với phục hình tạm hàm
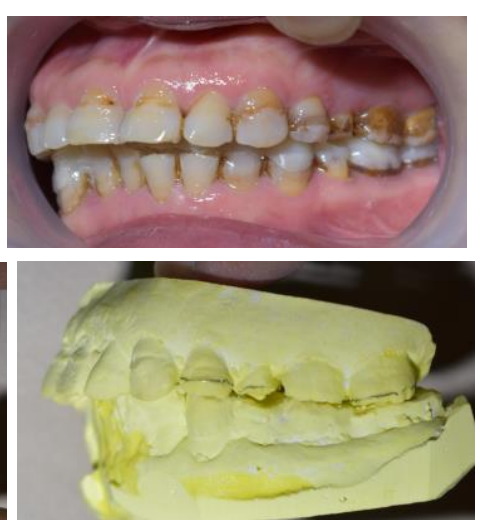

trên thì ở phía sau phủ lên mặt nhai răng hàm, nhưng vùng răng cửa trên thì đắp chủ yếu phía mặt lưỡi của của răng cửa đề tạo ra tiếp xúc giữa 2 hàm với hướng dẫn răng cửa và răng nanh tốt nhất có thể (hình 4).
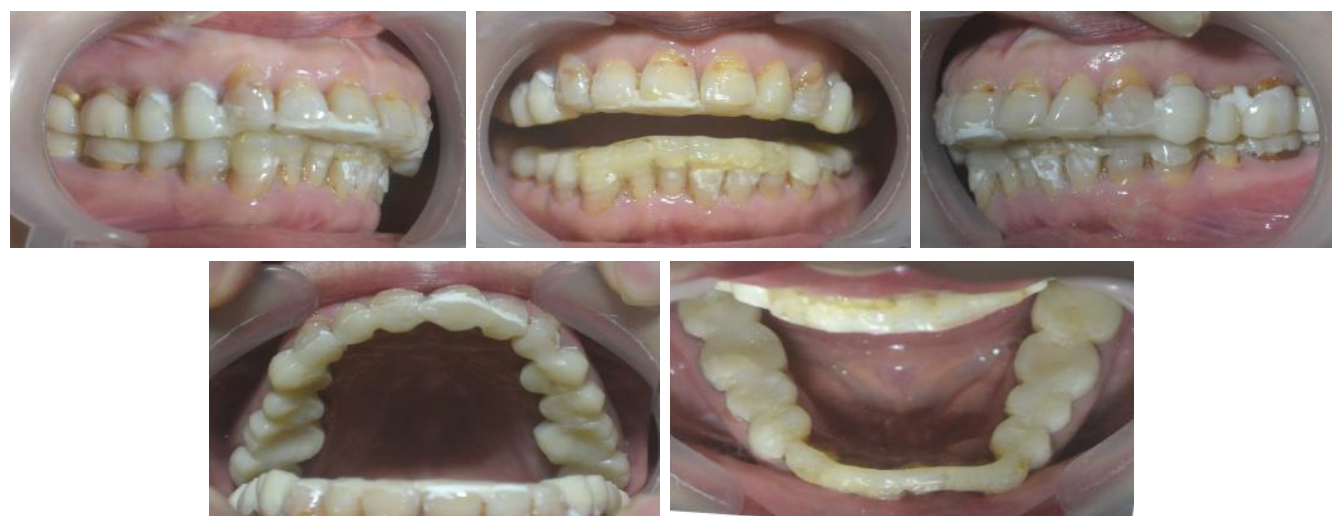

Hình 4: sau khi lắp phục hình tạm hàm trên, tạo chạm khớp đều trên tất cả các răng đồng thời tạo lại hướng dẫn răng nanh và răng cửa. 
Tiếp tục hẹn bệnh nhân tái khám hàng tuần để mài chỉnh trên phục hình tạm, đồng thời khám phát hiện tình trạng co thắt cơ và mỏi hàm do thay đổi tầm cắn. Sau 1 tháng theo dõi, bênh nhân có cảm giác thoải mái khi hai hàm ở tư thế nghỉ, khi ăn nhai và phát âm bình thường khi đấy bắt đầu tiến hành mài cùi đồng thời cả 2 hàm.
Khi mài cùi răng thì gần như chỉ mài chu vi răng hàm mà không mài mặt nhai răng hàm. Đối với vùng răng cửa trên để đảm bảo yêu câu thẩm mỹ thì mài nhiều hơn ở măt ngoài. Trong quá trình mài để đảm bảo không bị mất tầm cắn đã xác lập trước đó với phục hình tạm, chúng tôi mài cả 2 hàm nhưng 4 răng số 4 vẫn giữ nguyên tầm cắn với phục hình tạm (hình 5).
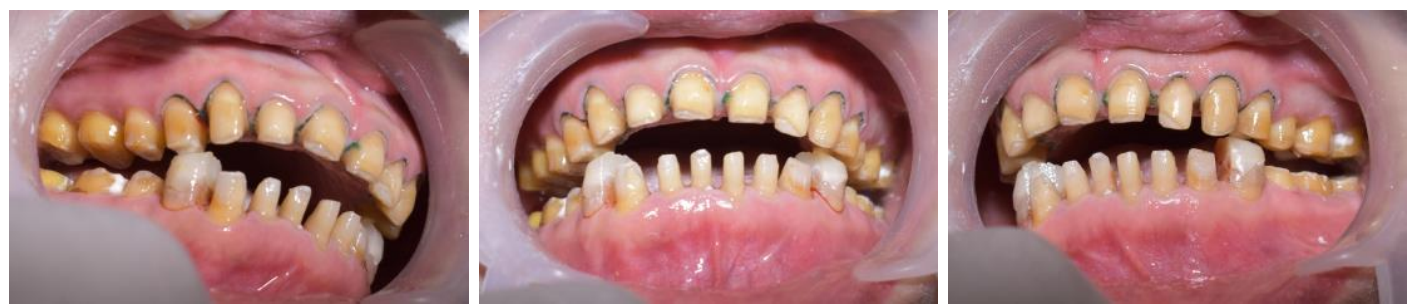

Hình 5: Mài chu vi thân răng mà không mài mặt nhai, giữ lại tầm cắn bằng việc để lại 4 răng số 4.

Sử dụng thìa lấy dấu đồng thời 2 hàm để ghi dấu cắn 2 hàm cho 1 thì lấy dấu. Lấy dấu 2 hàm bằng silicon đặc (Hình 6).
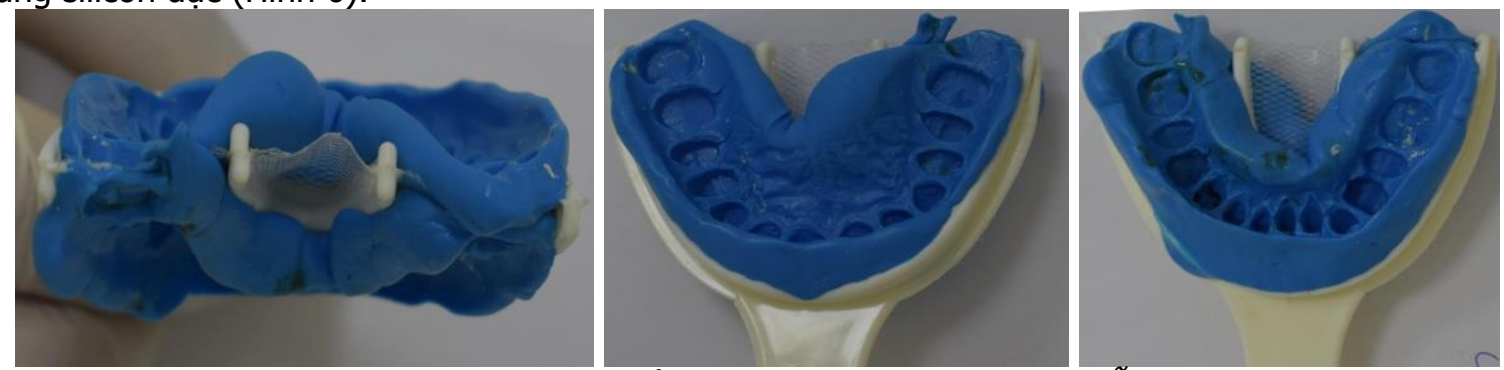

Hình 6: Lấy dấu 2 hàm bằng silicon đặc để ghi tầm cắn, lưu ý răng số 4 vẫn chưa được mài mặt nhai

Sau khi ghi xong tầm cắn chúng tôi mới tiến hành mài cùi nốt 4 răng số 4 . Và lấy dấu 2 hàm bằng silicon. Gứi xưởng để làm phục hình 2 hàm bằng vật liệu toàn sứ Ziconia vẽ màu. Bệnh nhân được gắn phục hình tạm để đánh giá các tiêu chí thẩm mỹ như chiều dài thân độ chìa của răng và thẩm mỹ khuôn mặt (hình 7)

\section{Hình 7: Đánh giá các tiêu chí thẩm mỹ với} phục hinh tạm

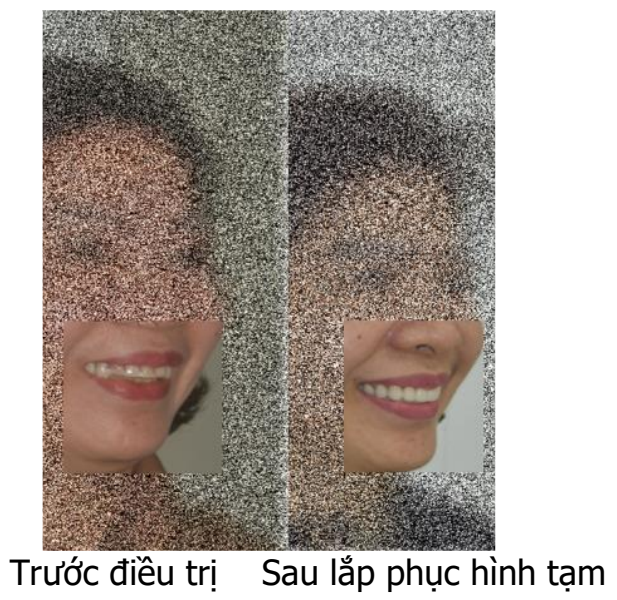

Sau khi bệnh nhân đồng ý các tiêu chí thẩm mỹ thì gửi mẫu hàm cho xưởng cùng với dấu của hàm răng tạm. Phục hình cuối cùng được gắn bằng chất gắn chuyên dụng U200 (hình 8).
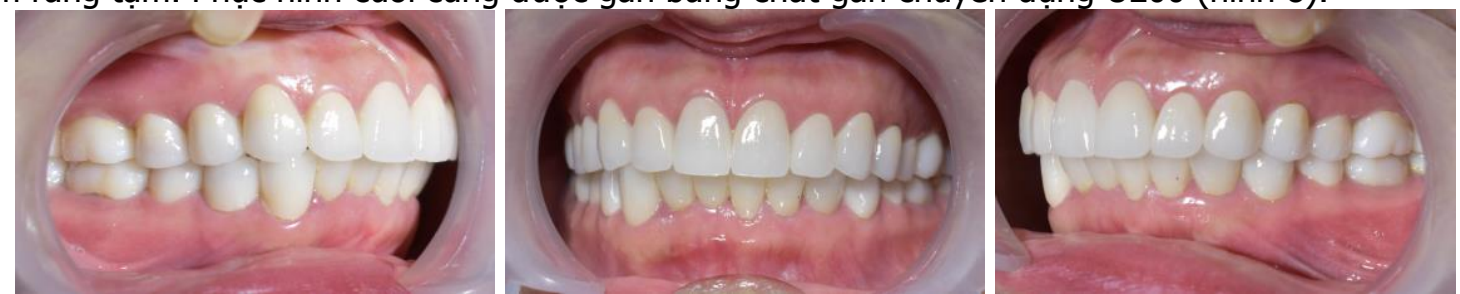


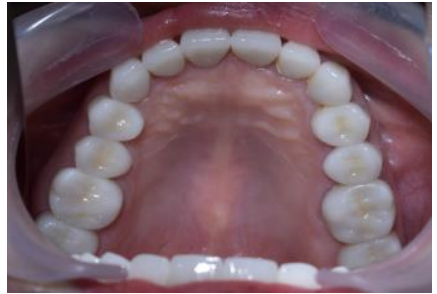

\section{BÀN LUẬN}

Mất mô răng có thể là kết quả của hai loại nguyên nhân:

- Nguyên nhân cơ học: ma sát và mài mòn

- Nguyên nhân hóa học: xói mòn.Theo nhiều nghiên cứu thì nguyên nhân chính gây mòn răng là do xói mòn hơn là do ma sát.

- Kết hợp của nhiều nguyên nhân: ở những bệnh nhân bị mòn răng, thường có nguyên nhân ma sát, đặc biệt là ở những bệnh nhân có sự kết hợp giữa khớp cắn lệch tâm và chen chúc răng trước, do lực nhai tác động theo chiều ngang nhiều hơn dẫn đến mòn bề mặt men.

Mài mòn (attrition). Đó là mất tổ chức răng thông qua sự tiếp xúc giữa răng và răng. Khám lâm sàng mặt mòn có đặc điểm phẳng, sáng bóng với các cạnh sắc nét.

Có hai nguyên nhân mài mòn răng: sinh lý hoặc bệnh lý.

Mài mòn răng sinh lý là mòn răng do các hoạt động chức năng bình thường như nhai và cắn.

Mài mòn răng bệnh lý, có thể do bốn nguyên nhân:

- Do giới hạn biên độ chuyển động hàm dưới.

- Do cản trở cắn.

- Do kích thích thần kinh (chứng chứng nghiến răng ban đêm)

- Do bất thường về cấu trúc răng, như chứng tạo men, tạo ngà không hoàn hảo.

Co mòn (Abrasion). Mòn răng do ma sát giữa răng và một tác nhân ngoại sinh.

Theo loại tác nhân ngoại sinh, có bốn nguyên nhân: do đánh răng, do ngậm tẩu thuốc, do thói quen gây sang chấn răng, do tục lệ của một số chủng tộc.

Xói mòn (Erosion). Là sự ăn mòn răng tiến triển và không hoàn nguyên không do vi khuẩn (sự tiếp xúc của răng với axit ngoại sinh hoặc nội sinh). khám lâm sàng soi mòn răng cho hình ảnh các mặt lõm hình đáy chén, bề mặt trơn, với các cạnh tròn.

Xoi mòn có thể do ba yếu tố căn nguyên:

- Yếu tố ngoại sinh như ăn nhiều đồ ngọt, nước ngọt, nước hoa quả và đường.

- Yếu tố nội sinh như chứng cuồng ăn, cắt dạ dày, trào ngược dạ dày-thực quản

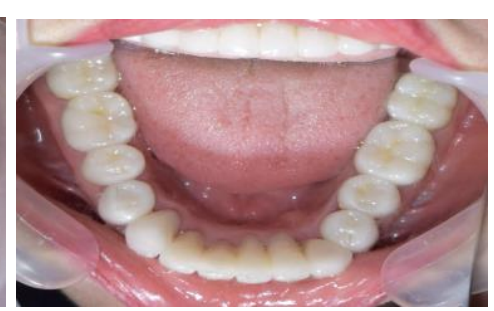

- Vồ căn.

Khai thác tiền sử bệnh nhân của chúng tôi không có thói quen ăn thức ăn ngọt hay bệnh lý dạ dày thực quản. bệnh nhân cũ̃ng không có tiền sử cợ mòn răng với tác nhân ngoại sinh, khớp cắn không lệch tâm rõ. Như vậy mòn răng trên bệnh nhân này là do mài mòn răng răng với đặc điểm lâm sàng là các cạnh sắc và mặt răng được mài bóng.

Việc chẩn đoán chính xác nguyên nhân và kế hoạch điều trị đúng là yếu tố quan trọng cho sự thành công của việc phục hình lại răng mòn.

Điều trị răng mòn có thể được chia thành 3 giai đoạn:

$\checkmark$ Đánh giá chính xác căn nguyên, tình trạng lâm sàng, chức năng và thẩm mỹ.

$\checkmark$ Giai đoạn điều trị phục hồi và phòng ngừa

$\checkmark$ Điều trị duy trì.

Trong giai đoạn phòng ngừa và phục hồi, đầu tiên cần cố gắng giảm ảnh hưởng của yếu tố bệnh nguyên. Bệnh nhân của chúng tôi sau khi lắp phục hình được cho mang máng bảo vệ ban đêm được dặn hạn chế ăn các thức ăn gây mòn răng; thay đổi cách đánh răng.

Trong nhiều trường hợp, chiều dọc của khớp cắn (kích thước dọc) được duy trì bởi sự mọc răng và sự phát triển của xương ổ răng. Khi răng bị mòn, xương ổ răng trải qua một quá trình thích nghi và bù đắp cho sự mất cấu trúc của răng để duy trì kích thước dọc. Do đó, nên chúng tôi rất thận trọng khi thay đổi kích thước dọc. vì nhiều nghiên cứu cho thấy việc tăng kích thước dọc ở những người nghiến răng gâyy quá tải nghiêm trọng cho răng và thường dẫn đến phá hủy phục hình hoặc chính răng tự nhiên [2].

Có một số nghiên cứu báo cáo về việc xác định kích thước dọc, trong đó có phương pháp đo khoảng trống liên hàm ở tư thế nghỉ. Niswonger báo cáo rằng khoảng trống liên hàm là 4/32"(3 mm) ở $87 \%$ bệnh nhân; $13 \%$ còn lại thay đổi từ 1/32" đến 11/32". Nis-wonger kết luận rằng khi răng dần mòn, cơ thể thích nghi bằng cách tạo ra những thay đổi cần thiết trong xương và mô để duy trì không gian. Mất răng hoặc mòn là những yếu tố tiềm ẩn làm thay đổi 
tính chất động lực học của hệ thống xương hàm [8].

Có nhiều phương pháp đánh giá sự thay đổi trong kích thước dọc: (a) Mất điểm tựa khớp cắn phía sau: mất răng sau hàm dưới và bệnh nhân không sử dụng hàm giả. Mất tầm cắn phía sau dẫn đến mòn quá nhiêuu và gãy các răng trước. (b) Tiền sử mòn: Sự mòn răng sinh lý có thể được bù đắp bằng quá trình mọc răng thụ động do quá trình bồi đắp của xi măng chân răng, nhưng sự mài mòn có thể vượt quá tốc độ mọc răng. (c) Đánh giá phát âm: Nếu rìa cắn răng cửa hàm dưới và mặt lưỡi của răng cửa hàm trên cách khoảng $1 \mathrm{~mm}$ thì nó tạo ra âm / $\mathrm{s} /$ bình thường. nếu tầm cắn tăng lên sẽ làm bệnh nhân thay đổi âm / s / thành âm / S /. (d) Khoảng nghỉ khớp cắn: so lồng múi tối đa với tư thế nghỉ, khi đo giữa đỉnh mũi và đỉnh cằm lớn hơn giá trị bình thường (thường từ $2-4 \mathrm{~mm}$ ). (e) Biểu hiện trên khuôn mặt: khóe mép rơi xuống thấp [7]. Bệnh nhân của chúng tôi đã được phối hợp các phương pháp này trong quá trình nâng tầm cắn.

Nhiều phân loại mòn răng khác nhau đã được đề xuất cho bệnh nhân cần phục hình toàn hàm, tuy nhiên, phẩn loại được áp dụng rộng rãi nhất là phân loại của Turner và Missirlian đưa ra vào năm 1984 [2] như sau:

- Loại 1: Mòn quá mức làm mất kích thước dọc khớp cắn. Khoảng cách giữa 2 hàm khi nói vị trí gần nhất của bệnh nhân cũng lớn hơn $1 \mathrm{~mm}$ và khoảng cách liên hàm khi nghỉ lớn hơn $4 \mathrm{~mm}$, có mất đường nét trên khuôn mặt nhẹ, chảy xệ khóe miệng.

- Loại 2: Mòn răng nặng nhưng không mất kích thước dọc, khoảng trống phục hình vẫn còn rộng. Bệnh nhân thường có tiền sử mòn răng dần do tật nghiến răng, thói quen răng miệng hoặc các yếu tố môi trường, nhưng kích thước dọc khớp cắn được duy trì nhờ vào việc mọc răng liên tục. Đây là loại mòn răng của bệnh nhân chúng tôi

- Loại 3: Mòn răng nặng nhưng không mất kích thước dọc, khoảng phục hình hẹp. Có sự mòn quá mức của các răng trước, và các răng sau mòn ít. Tư thế tương quan trung tâm trùng với khớp cắn trung tâm, khoảng cách phát âm gần nhất là $1 \mathrm{~mm}$ và khoảng nghỉ liên hàm 2$3 \mathrm{~mm}$. Trong những trường hợp như vậy phải có khoảng trống theo chiều đứng cho các vật liệu phục hình. Để làm được phục hình đòi hỏi phải chỉnh nha đánh lún răng, thay thế loại phục hình, phẫu thuật kéo dài thân răng, chỉnh sửa kích thước dọc từ từ. là dạng phục hình khó làm và dễ tai biến nhất.

Đã có nhiều nghiên cứu tìm khớp cắn lý tưởng sử dụng cho phục hình toàn hàm để tạo ra chức năng cơ và khớp tối ưu bên cạnh mục tiêu phục hồi mặt nhai của răng. Tuy nhiên tùy thuộc từng trường hợp lâm sàng cụ thể để lựa chọn qui trình phục hồ khớp cắn thích hợp giúp đạt được kết quả lâu dài có thể dự đoán được và chức năng khớp cắn tốt. Bệnh nhân của chúng tôi được xác định khớp cắn lý tưởng dựa theo 1 qui trình thận trọng, sau khi đánh giá cẩn thận các tiêu chí khớp cắn.

\section{KẾT LUÂ̂N}

Việc điều trị bệnh nhân mòn răng nặng ngày càng được quan tâm. Mục tiêu của phục hình toàn hàm là tái tạo, phục hồi và duy trì sức khỏe của toàn bộ hệ thống nhai. Phục hồi toàn hàm là một quy trình không hoàn nguyên và cần được khám cẩn thận để xác định bệnh nguyên, chọn lựa thời điểm điều trị thích hợp, qui trình điều trị thực hiện một cách thận trọng dựa trên kiến thức về các triết lý khác nhau.

Có nhiều triết lý phục hình toàn hàm khác nhau, và qui trình phục hình toàn hàm của chúng tôi đề xuất tương đối đơn giản, dễ thực hiện và mang lại sự thoải mái cho bệnh nhân.

\section{TÀI LIỆ THAM KHẢO}

1. Gopi Chander, N. and R. Venkat, An appraisa on increasing the occlusal vertical dimension in full occlusal rehabilitation and its outcome. J Indian Prosthodont Soc, 2011. 11(2): p. 77-81.

2. Sinnurkar, S., Multidisciplinary Approach for a Patient. International Journal of Science and Research, 2015. 6: p. 413-417.

3. Fed. germano, Clinical protocol with digital cad cam chairside workflow for the rehabilitation of severely worn dentition patients. ORAL \& Implantology, 2017: p. 247_260.

4. Tiwari, B., et al., Occlusal concepts in full mouth rehabilitation: an overview. J Indian Prosthodont Soc, 2014. 14(4): p. 344-51.

5. DeWood, G.M., <Gnathology and Pankey-MannSchuyler fulfilling the requirements of occlusion in oral rehabilitation.pdf $>$. Master's and Doctoral Projects, Medical College of Ohio, 2004.

6. Ram, S., et al., Full-mouth Rehabilitation of Worn Dentition by Hobo Twin-stage Philosophy: A Case Series. Journal of Contemporary Dentistry, 2019. 9(1): p. 17-24.

7. Abduo, J. and K. Lyons, Clinical considerations for increasing occlusal vertical dimension: a review. Aust Dent J, 2012. 57(1): p. 2-10.

8. K.S.L.P. Vidhiyasagar, Diagnosis and Management of Occlusal Wear A Case Report. J Indian Prosthodont Soc July-Sept 2013. 13 (3): : p. 366-372. 